\title{
Effect of overweight on gastrointestinal microbiology and immunology: correlation with blood biomarkers
}

\author{
Kirsti Tiihonen*, Arthur C. Ouwehand and Nina Rautonen \\ Danisco Finland Oy, Health and Nutrition, Sokeritehtaantie 20, FIN-02460 Kantvik, Finland \\ (Received 22 April 2009 - Revised 22 September 2009 - Accepted 12 October 2009 - First published online 24 November 2009)
}

\begin{abstract}
A cross-sectional study was carried out in order to compare intestinal microbiological and immunological biomarkers with blood glucose and lipids, satiety-related hormones and inflammatory biomarkers characterising differences between obese and normal weight subjects. Faecal and blood samples were obtained from twenty obese subjects with an average BMI of $32.9 \mathrm{~kg} / \mathrm{m}^{2}$ and twenty normal weight subjects with an average BMI of $23.3 \mathrm{~kg} / \mathrm{m}^{2}$. Blood insulin, TAG and leptin were significantly elevated, whereas concentrations of HDL and ghrelin were significantly decreased in the obese subjects. Inflammatory status in the obese subjects was characterised by a trend for elevated blood C-reactive protein (CRP; $P=0.06)$ and IL-6 $(P=0.02)$. The faecal microbial composition differed between the groups; less sulphate-reducing bacteria $(P=0.05)$ and a trend for less Bacteroides $(P=0.07)$ were measured for overweight subjects. Furthermore, an inverse correlation was demonstrated between faecal Bacteroides levels and waist circumference $(P=0.05)$. The faecal microbial metabolites differed between the groups; increased concentrations of branched-chain fatty acids, phenolics, valeric acid, di- and hydroxy acids were described in the obese subjects. No differences between the measured intestinal inflammatory biomarkers were detected. However, systemic inflammation (CRP and IL-6) was correlated with the faecal concentrations of phenolics and lactic acid $(P<0.05$ and 0.05 , and $P<0.01$ and 0.05 , respectively). In summary, weight-related differences were observed both in the intestinal microbial composition and its activity. The role of intestinal signals, such as phenolics and lactic acid in the development of weight-related problems, needs to be studied further.
\end{abstract}

Intestinal microbiota: Inflammation: Overweight

Overweightness and obesity have become globally common conditions that can significantly reduce quality of life and life expectancy ${ }^{(1)}$. Alongside overweight, the prevalence of metabolic syndrome is increasing ${ }^{(2)}$. Increased concentrations of blood lipids and glucose in overweight subjects are risk factors for the development of CVD and diabetes ${ }^{(3)}$. It is well documented that obesity is a systemic inflammatory condition, characterised by increased plasma concentrations of C-reactive protein (CRP) and inflammatory cytokines ${ }^{(4,5)}$. Furthermore, it has been demonstrated that there is a correlation between weight, or waist circumference, adiposity and the blood-inflammatory status ${ }^{(6,7)}$.

Changes in gastrointestinal (GI) functions in overweight subjects have not been studied extensively. Intestinal glucose and amino acid transporters are typically adapted to the luminal nutrient concentrations ${ }^{(8)}$. Excessive luminal nutrient load may exceed the absorptive capacity of the transporters ${ }^{(9)}$, allowing increased availability of nutrients for colonic microbes. Thus, nutrients not available in the colon of healthy normal weight subjects may have an impact on the composition of the microbial community and the amount of energy harvested from the diet. Recently, a new role for intestinal microbes and the production of $\mathrm{SCFA}^{(10,11)}$ in the development of obesity has been suggested. Specifically, body weight-based differences between the balance of the relative proportions of the two major intestinal bacterial phyla, Firmicutes and Bacteroidetes, have been described ${ }^{(10)}$.

The aim of the present study was to characterise the intestinal immunological and microbiological environment in obese and normal weight subjects in more detail, and furthermore, to correlate intestinal biomarkers with well-described blood biomarkers for obesity.

\section{Materials and methods}

\section{Study subjects}

In total, forty subjects were recruited to take part in the present study in the area of Kuopio, Eastern Finland. The main inclusion criteria of the study subjects were for them to be aged between 20 and 55 years and to have a BMI of $20-25 \mathrm{~kg} / \mathrm{m}^{2}$ for the normal weight group and a BMI of $30-37 \mathrm{~kg} / \mathrm{m}^{2}$ for the obese group. In addition, the subjects had to be accustomed to consuming a mixed diet with moderately low-fibre content (a typical fibre intake of less than $19 \mathrm{~g} / \mathrm{d}$ for men and $17 \mathrm{~g} / \mathrm{d}$ for women). The exclusion criteria were critical illness, inflammatory bowel disease, celiac disease or malignancy in the GI tract. Use of anti-obesity drugs, laxatives

Abbreviations: BCFA, branched-chain fatty acids; CRP, C-reactive protein; GI, gastrointestinal; PYY, peptide tyrosine-tyrosine. 
and weight control products was prohibited. Furthermore, regular (daily) use of probiotics, fibre supplements or bran as well as the regular and/or abundant use of non-steroidal anti-inflammatory drugs was not allowed. The use of antibiotics was prohibited for 3 months before and also during the study. Subjects with a tendency towards constipation (defecation frequency $<3 /$ week) and subjects with recent (within 1 month) severe acute diarrhoea were excluded. In addition, alcohol or drug abuses were exclusion criteria. The present study was conducted according to the guidelines laid down in the Declaration of Helsinki, and all procedures involving human subjects were approved by the Research Ethics Committee, Hospital District of Northern Savo. The purpose of the study was explained to the participants, and written informed consent was obtained from all subjects.

\section{Study design and background information}

In telephone screening, potential study subjects were interviewed on their consumption of fibre containing food items using an internet-based questionnaire (www.leipatiedotus.fi) ${ }^{(12)}$. The questionnaire calculated the daily fibre intake in grams per day. The cross-sectional study consisted of two study visits. On the first visit, the demographic data and other background information on the study subjects were collected on a structured form (background demographics and diet in Table 1). Furthermore, anthropometric measurements were taken and subjects were instructed how to collect the faecal samples. Body weight was measured twice on the first study visit on a digital scale (Scale Seca 707, Vogel \& Falke GmpH \& Co., Hamburg, Germany) and the mean was used in the results. Body height was measured with a Seca telescoping measuring rod, type 221 , to the nearest crossed millimetre. The waist circumference was measured at a level midway between the superior aspect of the iliac crest and the lower lateral margin of the ribs. The circumference was measured twice and the second measurement was used as the final result. Typically, study subjects are more relaxed during the second measurement and thus the last measurement is considered more reliable. No overnight fasting was requested before the anthropometric measurements. During the 1-week study period, subjects recorded in a diary all changes in their medication and health status as well as their bowel function. On the second study visit, subjects returned the faecal samples and blood samples were taken.

\section{Sample collection}

All blood samples were extracted after a 10- to 12-h overnight fast during the second study visit. The samples were collected to serum tubes for S-insulin, S-hs-CRP, S-leptin and S-adiponectin analysis; to citrate-containing tubes for B-glucose analysis; to gel tubes for total cholesterol, fS-LDL and fS-HDL and fS-TAG analysis; and to EDTA-containing tubes for P-IL-6, P-TNF- $\alpha$, P-ghrelin, P-peptide tyrosine-tyrosine (PYY) and P-orexin analysis. The samples were analysed as fresh (B-glucose, S-insulin, total cholesterol, LDL- and HDL-cholesterol and TAG) or stored at $-70^{\circ} \mathrm{C}$ (S-leptin, S-adiponectin, S-hs-CRP, P-IL-6, P-TNF- $\alpha$, P-ghrelin, P-PYY and P-orexin) until analysis. Three spot samples of faeces were collected in a $60 \mathrm{ml}$ specimen tube with an applicator. All faecal samples were placed immediately after collection into a home freezer or were freshly transferred, with a maximum of $1.5 \mathrm{~h}$ delay, for freezing in the study unit. Both frozen and fresh samples were transferred to the study unit in a polystyrene box with frozen cool bags. Thereafter, the samples were stored at $-20^{\circ} \mathrm{C}$ until analysed.

\section{Blood measurements}

Blood lipids, sugar and insulin. Serum total TAG, total-, LDL- and HDL-cholesterol were analysed by enzymatic photometric assay (Konelab 60i Clinical Chemistry Analyzer, Thermo Electron Corp., Vantaa, Finland) using commercial reagents (Konelab cholesterol, LDL-cholesterol, HDL-cholesterol and TAG, Thermo Electron Corp.) and plasma glucose by using commercial reagents (Konelab glucose, Thermo Electron Corp.). Also serum insulin was analysed by TR-FIA using commercial kits (AutoDELFIA ${ }^{\text {TMo }}$ insulin kit, Perkin-Elmer, Boston, MA, USA).

Table 1. Sex, age, life style, dietary restrictions, intake of dietary fibre, bowel function and use of food supplements of the study subjects ( $n$ 40) (Mean values with their standard errors)

\begin{tabular}{|c|c|c|c|c|c|c|c|c|}
\hline & \multicolumn{4}{|c|}{ Normal weight group (n 20) } & \multicolumn{4}{|c|}{ Obese group (n 20) } \\
\hline & Mean & SEM & $n$ & $\%$ & Mean & SEM & $n$ & $\%$ \\
\hline Men/women (number) & & & $8 / 12$ & & & & $8 / 12$ & \\
\hline Age (years) & $45 \cdot 0$ & $7 \cdot 2$ & & & $46 \cdot 2$ & $5 \cdot 8$ & & \\
\hline BMI $\left(\mathrm{kg} / \mathrm{m}^{2}\right)$ & $23 \cdot 3$ & $1 \cdot 6$ & & & 32.9 & $2 \cdot 3$ & & \\
\hline Waist circumference $(\mathrm{cm})$ & $82 \cdot 2$ & $7 \cdot 5$ & & & $107 \cdot 5$ & $7 \cdot 4$ & & \\
\hline Number of subjects doing regular physical exercise* & & & 17 & 85 & & & 13 & 65 \\
\hline Number of smokers & & & 3 & 15 & & & 4 & 20 \\
\hline Number of alcohol users & & & 17 & 85 & & & 15 & 75 \\
\hline Number of subjects having dietary restrictions (lactose etc.) & & & 5 & 25 & & & 6 & 30 \\
\hline Dietary intake of fibre $(\mathrm{g} / 24 \mathrm{~h})$ & $16 \cdot 1$ & 0.5 & & & $14 \cdot 9$ & 0.9 & & \\
\hline \multicolumn{9}{|l|}{ Number of subjects using food supplements } \\
\hline Vitamins, minerals & & & 6 & 30 & & & 7 & 35 \\
\hline Other food supplements ( $n$-fatty acids etc.) & & & 6 & 30 & & & 8 & 40 \\
\hline Defecation frequency as reported in the interview (times/d) & $1 \cdot 3$ & 0.9 & & & 1.3 & 0.7 & & \\
\hline
\end{tabular}

${ }^{*}$ At least half an hour, two to three times a week. 
Satiety-related peptides. Serum leptin and ghrelin were analysed by RIA (Multigamma 1261-001, Perkin-Elmer/ Wallac Oy, Turku, Finland) using commercial kits (Human Leptin RIA Kit, cat. no HL-81K, Linco Research Inc., St Charles, MO, USA and Ghrelin (Total) RIA Kit, cat. no GHRT-89HK, Linco Research Inc., respectively). Serum adiponectin was analysed by an immunoenzymometric assay using commercial kits (Human Adiponectin/Acrp30 Immunoassay, R\&D Systems Inc., Minneapolis, MN, USA). PYY was analysed by RIA (Multigamma 1261-001, Perkin-Elmer/ Wallac Oy) using commercial kits (PYY (Total) RIA Kit, cat. no. PYYT-66HK, Linco Research Inc.). Plasma orexinA concentrations were analysed with RIA using commercial kits (Orexin-A (Human, Rat, Mouse) RIA Kit; Cat no RK003-30, Phoenix Pharmaceuticals, Inc., Belmont, CA, USA).

Inflammatory biomarkers. IL- 6 and $\mathrm{TNF}-\alpha$ were analysed with solid phase ELISA method using commercial kits (Quantikine ${ }^{\circledR}$ HS/Human IL-6 immunoassay and Quantikine ${ }^{\circledR}$ HS/Human TNF- $\alpha$ Immunoassay, R\&D Systems Inc., Minneapolis, MN, USA). Hypersensitive CRP was analysed with turbidimetry (Hitachi 912, Roche, GmbH, Germany) using Tina-quant CRP (latex) high sensitive assay (Product number 1972855, Roche Diagnostics).

\section{Faecal measurements}

$D M, p H$, ions and energy. Immediately after melting, the frozen faecal samples were weighed for various physicochemical analyses. For DM determination, approximately $1 \mathrm{~g}$ faecal sample was weighed, dried at $105^{\circ} \mathrm{C}$ for $16 \mathrm{~h}$, cooled down in a desiccator to room temperature, reweighed and the DM content (\%) calculated. For $\mathrm{pH}$ measurements, $1 \mathrm{~g}$ faecal sample was mixed with $1 \mathrm{ml}$ distilled water and the $\mathrm{pH}$ measured immediately (SevenEasy $\mathrm{pH}$, Mettler Toledo GmbH, 8603 Schwerzenbach, Switzerland). For $\mathrm{Na}^{+}$and $\mathrm{K}^{+}$ analyses, $1 \mathrm{~g}$ faecal sample was washed and then dissolved in $\mathrm{HCl}$. The solution was diluted with water, and the $\mathrm{K}$ content of the solution was determined by an inductively coupled plasma emission spectrometer at wavelength $766.4 \mathrm{~nm}$ and the $\mathrm{Na}$ content at wavelength $589.5 \mathrm{~nm}$. The energy contents of the faecal samples were determined by an adiabatic bomb calorimeter.

Protein and fat. The faecal protein measurement was based on total $\mathrm{n}(N \times 6 \cdot 25=$ protein $)$ as analysed by the Kjeldahl method. Determination of the total faecal fat was modified from the American Organization of Analytical Chemists 963.15 method (1973; Fat in Cacao Products, Soxthlet Extraction Method). In short, the total amount of petrol diethyl ether-soluble fat was determined after hydrolysis gravimetrically. Fatty acids were analysed as their methyl esters (fatty acid methyl esters) by $\mathrm{GC}^{(13)}$.

Phenolic and acidic compounds. The method of analysis for phenolic and acidic compounds in human faeces was based on the method by Knust et al. ${ }^{(14)}$. Briefly, a faecal matrix was initially extracted with a phosphate buffer, and the extract was then acidified and re-extracted with a diethyl ether. Individual phenolic and acidic compounds were identified as their silyl derivatives by GC-MS and semi-quantitated using an internal surrogate standard (salicylic acid). Of the forty-six identified compounds, twenty belonged to di- and hydroxy acids, eleven belonged to phenolics, ten belonged to fatty acids and four belonged to sterols. The results were expressed as a sum of the compounds belonging to each subgroup. Moreover, the individual compounds (succinic acid, lactic acid, 3-OH-benzenepropanoic acid and cholesterol) with the highest concentrations in the subgroups were selected for more detailed statistical analysis.

Soluble and insoluble carbohydrates. To separate the soluble and insoluble carbohydrates from faecal samples, $1 \mathrm{~g}$ faeces was weighed into a centrifuge tube and $9 \mathrm{ml}$ PBS was added (the PBS consisted of $8.5 \mathrm{~g} \mathrm{NaCl}, 1.21 \mathrm{~g} \mathrm{~K}_{2} \mathrm{HPO}_{4}$, $0.34 \mathrm{~g} \mathrm{KH}_{2} \mathrm{PO}_{4}, 0.5 \mathrm{~g} \mathrm{NaN}_{3}$ (to prevent bacterial growth), $1 \mathrm{mM}$ phenylmethyl sulphonium fluoride (to prevent serine proteases), $2 \mathrm{~mm}$ iodoacetamide (to inhibit cystein-containing enzymes), $10 \mathrm{~mm}$ EDTA (to inhibit metalloproteases) and 1 litre $\mathrm{H}_{2} \mathrm{O}$ ) and stored on ice while weighing other tubes. The samples were shaken vigorously for $1 \mathrm{~h}$ at $4^{\circ} \mathrm{C}$ and then centrifuged for $30 \mathrm{~min}$ at $4^{\circ} \mathrm{C}$ at $15000 \mathrm{~g}$. The clear supernatants were used for soluble carbohydrate analysis, and the pellet was used for the analysis of insoluble polysaccharides. The samples were stored at $-20^{\circ} \mathrm{C}$ until analysed.

The extraction of soluble carbohydrates from faecal supernatants was modified from the method described by Miller \& Hoskins $^{(15)}$. The faecal supernatants were centrifuged in a $35 \mathrm{ml}$ tube for $30 \mathrm{~min}$ at $4^{\circ} \mathrm{C}$ at $15000 \mathrm{~g}$ to remove any particulate matter. The clear faecal supernatant was (via filter through a $0.45 \mu \mathrm{m}$ filter) transferred to another centrifuge tube and $25 \mathrm{ml}$ ice-cold $\left(-18^{\circ} \mathrm{C}\right)$ ethanol was added to a final percentage of $70-80 \%$. The samples were mixed and allowed to stand at $4^{\circ} \mathrm{C}$ for $1 \mathrm{~h}$. After centrifugation at $4^{\circ} \mathrm{C}$ for $20 \mathrm{~min}$ at $10000 \mathrm{~g}$, the supernatants were discarded and the pellets were dissolved in $1 \mathrm{ml}$ water. The amount of soluble carbohydrates is the sum of hydrolysed hexoses and amino sugars. To hydrolyse hexoses in the soluble carbohydrate, a fraction of $0.1 \mathrm{ml}$ of the faecal suspension or the hexose standard solution (fucose, arabinose, rhamnose, galactose, xylose, glucose and mannose) was pipetted into a $2 \mathrm{ml}$ microfuge vial, and $0.1 \mathrm{ml} 4 \mathrm{M}$ trifluoroacetic acid was added. The samples were incubated at $100^{\circ} \mathrm{C}$ for $3 \mathrm{~h}$ and evaporated to dryness. The samples were dissolved in $1 \mathrm{ml}$ water and filtered through a $0.45 \mu \mathrm{m}$ membrane filter. The separation and analyses of hexoses were made using high $\mathrm{pH}$ ion exchange chromatography (HPLC) and a pulsed electrochemical detector. The analytical column was CarboPac PA1 $(4 \mathrm{~mm} \times 250 \mathrm{~mm})$, and the separation was done using a gradient elution with a mobile phase that consisted of a mixture of water and $0.2 \mathrm{M} \mathrm{NaOH}$. To hydrolyse amino sugars in a soluble carbohydrate, a fraction of $0.1 \mathrm{ml}$ of the faecal suspension or the standard solution (galactose amine and glucose amine) was pipetted into a $2 \mathrm{ml}$ microfuge vial, and $0.1 \mathrm{ml} 8 \mathrm{M} \mathrm{HCl}$ was added. The samples were incubated at $100^{\circ} \mathrm{C}$ for $5 \mathrm{~h}$ and evaporated to dryness. The samples were dissolved in $2 \mathrm{ml}$ water and filtered through a $0.45 \mu \mathrm{m}$ membrane filter. The separation and analyses of glucose amine and galactose amine were made by HPLC-pulsed electrochemical detector as described earlier.

To analyse the insoluble carbohydrates in the faecal samples, $2 \mathrm{ml}$ of $60 \%$ ice-cold $\mathrm{H}_{2} \mathrm{SO}_{4}$ was added to the solid pellet obtained after separation of the soluble and insoluble faecal fractions (see above). A glass rod was used to disperse the pellet thoroughly. The samples were allowed to stand at room temperature $\left(20-25^{\circ} \mathrm{C}\right)$ for $1 \mathrm{~h}$, then $22 \mathrm{ml}$ water was added to the samples and they were kept at $100^{\circ} \mathrm{C}$ for $5 \mathrm{~h}$. The samples 
were allowed to cool and then diluted to $50 \mathrm{ml}$ with water and filtered through a $0.45 \mu \mathrm{m}$ membrane filter. The samples were further diluted $1 / 10$ with $20 \mathrm{~mm} \mathrm{NaOH}$. The amino sugars and hexoses were analysed by HPLC-pulsed electrochemical detector as described earlier.

Ammonia, SCFA and biogenic amines. Ammonia, SCFA and branched-chain fatty acids (BCFA) concentrations in faecal samples were measured according to a method of Ouwehand et al. ${ }^{(16)}$. The biogenic amines in faeces were analysed using the method described by Saarinen ${ }^{(17)}$.

\section{Microbial analyses}

Total microbial counts. The total bacterial cell counts in digesta samples were determined by flow cytometry (FACSCalibur, Becton Dickinson, Franklin Lakes, NJ, USA) as previously described $^{(18)}$. The bacterial fractions were recovered by suspending faecal samples in a $50 \mathrm{~mm}$ sodium phosphate buffer ( $\mathrm{pH}$ 9.0), followed by centrifugation (48000 $\mathrm{g}$, $30 \mathrm{~min}, 22^{\circ} \mathrm{C}$ ) and washing. The cell samples were diluted, fixed and stained with the fluorescent nucleic acid-binding dye SYTO 24 (Molecular Probes, Leiden, The Netherlands). The results were expressed as the quantity of bacteria/g fresh digesta weight.

DNA extraction and PCR. DNA was extracted from the washed bacteria using the method described by Apajalahti et al. ${ }^{(19)}$, whereby bacteria were subjected to five freezethaw cycles and subsequently treated with lysozyme $\left(17.5 \mathrm{mg} / \mathrm{ml}, 4 \mathrm{~h}, 37^{\circ} \mathrm{C}\right)$ and proteinase $\mathrm{K}(0.1 \mathrm{mg} / \mathrm{ml}, 1 \mathrm{~h}$, $\left.37^{\circ} \mathrm{C}\right)$. The recovered bacterial DNA was used to quantify total bifidobacteria, lactobacilli, Clostridium group XIVab, Clostridium perfringens, Bacteroides and sulphate-reducing bacteria using primers and probes as described in Table 2.

Quantitative real-time PCR was performed using $1 \mu \mathrm{g}$ isolated bacterial genomic DNA. A $25-\mu 1$ amplification reaction consisted of $1 \times$ TaqMan Universal Master Mix (Applied Biosystems, Forster City, CA, USA) with $300 \mathrm{~nm}$ of both reverse and forward primers, and $200 \mathrm{~nm}$ TaqMan probe (Applied Biosystems). All assays were run on an ABI Prism 7000 Sequence Detection System (Applied Biosystems) using the instrument's default settings for thermal cycling and fluorescence measurements. For standard curves, bacterial genomic DNA from $C$. perfringens (ATCC 13124) and inhouse isolated genomic DNA from Desulfovibrio intestinalis (DSM 11275) were applied. Based on the genomic sizes, the weight of one copy of each of the $C$. perfringens and $D$. intestinalis genome was calculated, and the amount of chromosomes in $1 \mathrm{pg}$ was estimated. Standard amplification curves were constructed by using 1, 10, 100 and $1000 \mathrm{pg}$ bacterial genomic DNA as a template. The results are expressed as the quantity of bacteria/g faeces.

\section{Immunological analyses}

The concentrations of $\operatorname{IgA}, \mathrm{TNF}-\alpha$, calprotectin and $\mathrm{PGE}_{2}$ were measured from the soluble fraction of the faeces as previously described $^{(16)}$. Briefly, the frozen samples were thawed and extracted with bovine serum albumin and stored at $-20^{\circ} \mathrm{C}$ before analysis. Concentrations of IgA, TNF- $\alpha$ and $\mathrm{PGE}_{2}$ were determined with an ELISA in accordance with the respective manufacturer's instructions (E80-102, Bethyl Laboratories, Inc., Montgomery, TX, USA; Biosource Europe S.A., Nivelles, Belgium; Cayman Chemical Company, Ltd, Ann Arbor, MI, USA), and the results were expressed as $\mu \mathrm{g}$ or pg per gram fresh digesta weight.

\section{Statistical analyses}

The basic statistics (mean and standard error) were applied to the data. The comparison of normal weight and obese group means was carried out using the two-sample $t$ test, and a $P$-value lower than 0.05 was considered as significant. For addressing associations between inflammatory blood biomarker and intestinal biomarkers, Pearson correlation coefficients were calculated by combining the data from both groups. The association between the parameters was considered significant if the $P$-value was below $0 \cdot 05$.

\section{Results}

A number of different biomarkers both from blood and faecal samples were measured from twenty normal weight and twenty obese subjects. The waist circumference was on average 82 and $108 \mathrm{~cm}$, and the BMI was 23 and $33 \mathrm{~kg} / \mathrm{m}^{2}$, in the normal weight and obese subjects, respectively (Table 1).

\section{Blood biomarkers}

Concentrations of blood insulin and TAG were higher $(P<0.001$ and $P=0.026$, respectively), whereas concentrations of HDL-cholesterol were lower in the obese subjects $(P=0 \cdot 006)$. Blood glucose, total cholesterol and LDL-cholesterol were similar in both groups. The inflammatory biomarkers, CRP and IL-6, were higher in the obese subjects $(P=0.055$ and 0.024$)$, whereas concentrations of TNF- $\alpha$ were similar in both groups. Of the measured satiety hormones,

Table 2. Primers and probes used to quantify selected members the faecal microbiota

\begin{tabular}{|c|c|c|c|c|}
\hline Target & Forward & Reverse & Probe & Reference \\
\hline Bifidobacterium & CCT GGT AGT CCA CGC CGT AA & CAG GCG GGA TGC TTA ACG & ATC CAG CAT CCA CCG & Makivuokko et al. ${ }^{(54)}$ \\
\hline Lactobacillus & TGG AAA CAG RTG CTA ATA CCG & GTC CAT TGT GGA AGA TTC CC & & Byun et al. ${ }^{(55)}$ \\
\hline $\begin{array}{l}\text { Clostridium } \\
\text { perfringens }\end{array}$ & $\begin{array}{l}\text { TTT GGA GAT ATA GAT ACT CCA } \\
\text { TAT CAT CCT }\end{array}$ & $\begin{array}{l}\text { GTG CAA AAG TCT CAA ACT TAA } \\
\text { CAT GTC }\end{array}$ & $\begin{array}{l}\text { TAA TGT TAC TGC CGT } \\
\text { TGA T }\end{array}$ & Tiihonen et al. ${ }^{(30)}$ \\
\hline $\begin{array}{l}\text { Clostridium } \\
\text { group XIVab }\end{array}$ & GAW GAA GTA TYT CGG TAT GT & CTA CGC WCC CTT TAC AC & & Song et al. ${ }^{(56)}$ \\
\hline Bacteroides & GGC GAC CGG CGC ACG GG & GRC CTT CCT CTC AGA ACC C & & Nakanishi et al. ${ }^{(57)}$ \\
\hline Sulphate reducers & GGC GCT GAA ATG ACC ATG AT & GGC CGT AAC CGT CCT TGA A & TTC GTG CCC GCC CG & Tiihonen et al. ${ }^{(30)}$ \\
\hline
\end{tabular}


Table 3. Blood biomarkers in the obese and normal weight subjects

(Mean values with their standard errors)

\begin{tabular}{|c|c|c|c|c|c|c|c|}
\hline \multirow[b]{2}{*}{ Variable } & \multicolumn{3}{|c|}{ Normal weight group } & \multicolumn{3}{|c|}{ Obese group } & \multirow[b]{2}{*}{$P$} \\
\hline & $n^{\star}$ & Mean & SEM & $n^{*}$ & Mean & SEM & \\
\hline \multicolumn{8}{|c|}{ Biomarkers of sugar and lipid metabolism } \\
\hline Total cholesterol $(\mathrm{mmol} / \mathrm{l})$ & 20 & 4.65 & 0.19 & 20 & 4.49 & 0.19 & 0.568 \\
\hline LDL-cholesterol (mmol/l) & 20 & 2.95 & 0.14 & 20 & 2.95 & 0.16 & 0.981 \\
\hline HDL-cholesterol (mmol/l) & 20 & 1.57 & $0 \cdot 10$ & 20 & 1.19 & 0.09 & $0.006 \dagger$ \\
\hline Total TAG $(\mathrm{mmol} / \mathrm{l})$ & 20 & 0.94 & 0.10 & 20 & 1.54 & 0.23 & $0.026 \dagger$ \\
\hline Fasting plasma glucose (mmol/l) & 20 & $5 \cdot 32$ & 0.17 & 19 & 5.59 & 0.12 & 0.198 \\
\hline Fasting serum insulin (mU/l) & 20 & $5 \cdot 10$ & 0.67 & 19 & $10 \cdot 21$ & 1.00 & $0.0001 \dagger$ \\
\hline \multicolumn{8}{|l|}{ Inflammatory biomarkers } \\
\hline Hypersensitive CRP (mg/l) & 20 & 1.23 & 0.38 & 20 & 2.50 & 0.52 & 0.055 \\
\hline $\mathrm{IL}-6(\mathrm{pg} / \mathrm{ml})$ & 20 & 0.85 & 0.13 & 19 & 1.77 & 0.36 & $0.024 \dagger$ \\
\hline TNF- $\alpha(p g / m l)$ & 20 & 1.00 & 0.24 & 20 & 1.09 & 0.12 & 0.732 \\
\hline \multicolumn{8}{|l|}{ Satiety-related hormones } \\
\hline Adiponectin $(\mu \mathrm{g} / \mathrm{ml})$ & 20 & $10 \cdot 32$ & 1.61 & 20 & 8.53 & 1.60 & 0.436 \\
\hline Ghrelin (pg/ml) & 20 & $1058 \cdot 7$ & 79.8 & 20 & $840 \cdot 7$ & 58.8 & $0.034 \dagger$ \\
\hline Leptin $(\mathrm{ng} / \mathrm{ml})$ & 20 & 6.89 & 1.14 & 20 & 22.75 & 2.95 & $<0.0001 \dagger$ \\
\hline PYY $(\mathrm{pg} / \mathrm{ml})$ & 20 & $70 \cdot 84$ & 3.32 & 20 & 80.83 & $6 \cdot 38$ & 0.176 \\
\hline Orexin (pg/ml) & 20 & $12 \cdot 13$ & 0.67 & 19 & 14.51 & 2.49 & 0.366 \\
\hline
\end{tabular}

CRP, C-reactive protein; PYY, peptide tyrosine-tyrosine.

*The sample size used for calculating the descriptive statistics. $n$ is smaller than twenty in some cases due to missing data. Two-sample $t$ test was used to compare the mean values between the two groups.

†A $P$-value $<0.05$ was considered to indicate significant difference between the groups.

concentrations of leptin were higher and concentrations of ghrelin were lower in the obese subjects $(P<0.0001$ and $P=0 \cdot 03$, respectively). Concentrations of adiponectin, PYY and orexin were similar in both groups (Table 3 ).

\section{Faecal measurements}

Chemical composition of the faecal samples was studied with focus on the available nutrients and energy (Table 4).
The remaining measured energy in the faecal samples was similar in both groups, as well as the other measured physico-chemical properties (faecal weight, DM content, $\mathrm{pH}$, and concentrations of $\mathrm{Na}^{+}$and $\mathrm{K}^{+}$), with the exception of concentrations of ammonia and carbohydrates that showed a trend for higher levels in the obese subjects ( $P=0.15$ and $0 \cdot 14$, respectively). The residual concentrations of macronutrients, proteins and fats were similar in both groups.

Table 4. Chemical composition of faeces from the normal weight and obese subjects

(Mean values with their standard errors)

\begin{tabular}{|c|c|c|c|c|c|c|c|}
\hline \multirow[b]{2}{*}{ Variable } & \multicolumn{3}{|c|}{ Normal weight group } & \multicolumn{3}{|c|}{ Obese group } & \multirow[b]{2}{*}{$P$} \\
\hline & $n^{*}$ & Mean & SEM & $n^{*}$ & Mean & SEM & \\
\hline \multicolumn{8}{|l|}{ Physico-chemical } \\
\hline Faecal weight $(\mathrm{g} \mathrm{fw})$ & 20 & 221 & 29 & 20 & 231 & 25 & 0.800 \\
\hline DM (\%) & 20 & $22 \cdot 3$ & 0.8 & 20 & 23.3 & 1.5 & 0.573 \\
\hline $\mathrm{pH}$ & 20 & $7 \cdot 13$ & $0 \cdot 10$ & 20 & $7 \cdot 01$ & 0.09 & 0.387 \\
\hline Ammonia (mmol/kg fw) & 20 & $22 \cdot 6$ & 1.6 & 19 & $26 \cdot 6$ & $2 \cdot 2$ & 0.151 \\
\hline $\mathrm{Na}^{+}(\mathrm{g} / \mathrm{kg} \mathrm{fw})$ & 8 & 0.25 & 0.08 & 8 & 0.32 & 0.08 & 0.525 \\
\hline$K^{+}(g / k g ~ f w)$ & 8 & 4.54 & 0.37 & 8 & 4.02 & 0.25 & 0.257 \\
\hline Energy (kJ/100 g fw) & 8 & 415 & 36 & 8 & 425 & 29 & 0.829 \\
\hline \multicolumn{8}{|c|}{ Residual macronutrients ( $\mathrm{g} / \mathrm{kg} \mathrm{fw})$} \\
\hline Protein & 20 & $75 \cdot 0$ & $3 \cdot 8$ & 20 & $76 \cdot 6$ & $5 \cdot 7$ & 0.814 \\
\hline Carbohydrates & 20 & $26 \cdot 6$ & 1.4 & 20 & 30.5 & $2 \cdot 2$ & 0.140 \\
\hline Soluble carbohydrates & 20 & $1 \cdot 13$ & 0.19 & 20 & 1.23 & 0.22 & 0.724 \\
\hline Insoluble carbohydrates & 20 & $25 \cdot 5$ & 1.5 & 20 & $29 \cdot 3$ & $2 \cdot 2$ & 0.150 \\
\hline Fat & 8 & $36 \cdot 8$ & $8 \cdot 2$ & 8 & $24 \cdot 7$ & 3.9 & 0.201 \\
\hline Sum of fatty acids & 8 & 2.23 & 0.84 & 8 & 3.54 & 1.59 & 0.480 \\
\hline Sum of sterols $†$ & $8(3)$ & 0.54 & 0.28 & $8(3)$ & 0.25 & 0.13 & 0.350 \\
\hline Cholesterolf & $8(4)$ & 0.49 & 0.28 & 7 (4) & 0.06 & 0.03 & 0.170 \\
\hline
\end{tabular}

fw, fresh digesta weight.

* The sample size used for calculating the descriptive statistics including the number of samples below the detection limits (given in parenthesis). For calculation of the mean values, the data below detection limits were set to half of the limit value. Two-sample $t$ test was used to compare the mean values between the two groups.

† Detection limit $0.01 \mathrm{~g} / \mathrm{kg} \mathrm{fw}$.

$\ddagger$ Detection limit $0.01 \mathrm{~g} / \mathrm{kg} \mathrm{fw}$. 
While the total concentration of bacteria was similar, the microbial composition was different in the obese and normal weight subjects. The level of sulphate-reducing bacteria $(P=0.05)$ and Bacteroides $(P=0.07)$ appeared higher in the normal weight subjects than in the obese subjects (Table 5). Of the microbial metabolites, the sum of SCFA was similar in both groups. However, the concentrations of lactic acid and valeric acid were different $(P=0.08$ and 0.04$)$ between the study groups (Table 5). The sum of BCFA $(P=0.03)$ was higher in the obese subjects, as were the two main components, 2-methylbutyric acid and isovaleric acid ( $P=0.02$ and 0.03 , respectively). However, neither the sum of biogenic amines nor any of the single biogenic amines differed significantly between the groups. The sum of phenolic concentrations was significantly higher in the obese subjects $(P=0.02)$. In more detail, the 3-OH-benzenepropanoic acid concentrations were elevated in the obese subjects $(P=0 \cdot 06)$.

No differences were detected in the concentrations of faecal immune markers, IgA, TNF- $\alpha$, calprotectin and $\mathrm{PGE}_{2}$ (Table 5).

\section{Correlations between blood inflammatory biomarkers and intestinal biomarkers}

It was of special interest to study the correlations between inflammatory blood biomarkers and the intestinal biomarkers. Serum CRP and IL-6 appeared to be correlated, especially

Table 5. Faecal microbes and microbial metabolites in the normal and obese subjects (Mean values with their standard errors)

\begin{tabular}{|c|c|c|c|c|c|c|c|}
\hline \multirow[b]{2}{*}{ Variable } & \multicolumn{3}{|c|}{ Normal weight group } & \multicolumn{3}{|c|}{ Obese group } & \multirow[b]{2}{*}{$P$} \\
\hline & $n^{\star}$ & Mean & SEM & $n^{\star}$ & Mean & SEM & \\
\hline \multicolumn{8}{|l|}{ Microbes (log10 cells/g fw) } \\
\hline Total counts & 20 & $1.84 \times 10^{11}$ & $2.05 \times 10^{10}$ & 20 & $2.03 \times 10^{11}$ & $2.08 \times 10^{10}$ & 0.523 \\
\hline Clostridium group XIVab & 20 & $3.77 \times 10^{10}$ & $4.12 \times 10^{9}$ & 20 & $3.33 \times 10^{10}$ & $3.29 \times 10^{9}$ & 0.403 \\
\hline Bacteroidetes & 20 & $5.33 \times 10^{9}$ & $1.06 \times 10^{9}$ & 20 & $2.72 \times 10^{9}$ & $9.41 \times 10^{8}$ & 0.074 \\
\hline Bifidobacterium & 20 & $4.33 \times 10^{9}$ & $1.18 \times 10^{9}$ & 20 & $3.45 \times 10^{9}$ & $6.68 \times 10^{8}$ & 0.523 \\
\hline Lactobacillus & 20 & $3.64 \times 10^{8}$ & $1.53 \times 10^{8}$ & 20 & $4.26 \times 10^{8}$ & $2.04 \times 10^{8}$ & $0 \cdot 810$ \\
\hline Sulphate reducers $†$ & $20(12)$ & $3.62 \times 10^{7}$ & $1.7 \times 10^{7}$ & $20(12)$ & $1.36 \times 10^{6}$ & $1.28 \times 10^{6}$ & 0.055 \\
\hline Clostridium perfringens $\ddagger$ & $20(8)$ & $1.43 \times 10^{5}$ & $8.81 \times 10^{4}$ & $20(6)$ & $2.54 \times 10^{3}$ & $1.19 \times 10^{3}$ & 0.128 \\
\hline Sum of SCFA (mmol/kg fw) & 20 & $67 \cdot 31$ & $6 \cdot 22$ & 20 & $78 \cdot 79$ & $6 \cdot 19$ & $0 \cdot 199$ \\
\hline Acetic acid & 20 & $42 \cdot 13$ & $3 \cdot 84$ & 20 & $47 \cdot 15$ & $3 \cdot 80$ & 0.359 \\
\hline Propionic acid & 20 & $11 \cdot 50$ & $1 \cdot 19$ & 20 & $13 \cdot 64$ & $1 \cdot 34$ & $0 \cdot 241$ \\
\hline Butyric acid & 20 & $11 \cdot 28$ & 1.42 & 20 & $14 \cdot 73$ & 1.47 & 0.100 \\
\hline Valeric acid & 20 & 1.84 & $0 \cdot 11$ & 20 & $2 \cdot 45$ & $0 \cdot 25$ & $0.036 \S$ \\
\hline Capronic acid\| & 20 & 0.525 & 0.132 & 20 & 0.780 & 0.224 & 0.335 \\
\hline Sum of BCFA (mmol/kg fw) & 8 & $2 \cdot 98$ & $0 \cdot 24$ & 20 & $3 \cdot 89$ & $0 \cdot 33$ & $0.034 \S$ \\
\hline 2-Methylbutyric acid & 20 & $0 \cdot 747$ & 0.064 & 20 & $0 \cdot 101$ & 0.088 & $0.023 \S$ \\
\hline Isovaleric acid & 20 & 0.945 & 0.073 & 20 & $1 \cdot 255$ & $0 \cdot 108$ & $0.026 \S$ \\
\hline Isobutyric acid & 20 & $1 \cdot 29$ & 0.11 & 20 & 1.61 & 0.14 & 0.088 \\
\hline Sum of biogenic amines (nmol/kg fw) & 19 & 2829 & 727 & 20 & 2175 & 360 & 0.428 \\
\hline Methylamine & 19 & $419 \cdot 17$ & $42 \cdot 37$ & 20 & $409 \cdot 12$ & $49 \cdot 12$ & 0.878 \\
\hline Phenylethylamine & $19(7)$ & $72 \cdot 81$ & $17 \cdot 21$ & $20(4)$ & 88.93 & $19 \cdot 23$ & 0.537 \\
\hline Putrescineq & $19(2)$ & $898 \cdot 77$ & $490 \cdot 01$ & $20(2)$ & $477 \cdot 57$ & $122 \cdot 94$ & 0.414 \\
\hline Cadaverine & $19(3)$ & $697 \cdot 68$ & $315 \cdot 72$ & $19(1)$ & $560 \cdot 38$ & $268 \cdot 68$ & 0.742 \\
\hline Histamine ${ }^{\star \star}$ & $19(13)$ & $17 \cdot 18$ & $4 \cdot 31$ & $20(14)$ & $35 \cdot 77$ & $14 \cdot 03$ & $0 \cdot 218$ \\
\hline Tyramine & $19(11)$ & $28 \cdot 46$ & $7 \cdot 29$ & $20(10)$ & $35 \cdot 61$ & $10 \cdot 66$ & 0.587 \\
\hline Spermidine & 19 & $633 \cdot 77$ & $53 \cdot 29$ & 20 & $549 \cdot 62$ & $51 \cdot 89$ & $0 \cdot 265$ \\
\hline Spermine & 19 & $42 \cdot 06$ & $6 \cdot 33$ & 20 & $31 \cdot 64$ & $3 \cdot 28$ & 0.155 \\
\hline Sum of di- and hydroxy acids (mg/kg fw) & 8 & $426 \cdot 5$ & 65.5 & 8 & $765 \cdot 5$ & $127 \cdot 4$ & $0.033 \S$ \\
\hline Lactic acid†† & $8(2)$ & $67 \cdot 13$ & $19 \cdot 16$ & $8(1)$ & 249 & $88 \cdot 80$ & 0.082 \\
\hline Succinic acid†† & $8(1)$ & $103 \cdot 9$ & $39 \cdot 4$ & $8(1)$ & 173 & $40 \cdot 8$ & 0.243 \\
\hline Sum of phenolic acids (mg/kg fw) & $8(3)$ & $305 \cdot 6$ & $61 \cdot 6$ & $8(2)$ & $723 \cdot 3$ & 137.9 & $0.021 \S$ \\
\hline 3-OH-Benzene propanoic acid†† & 8 & $163 \cdot 1$ & $59 \cdot 9$ & 8 & 519 & $151 \cdot 6$ & 0.056 \\
\hline \multicolumn{8}{|l|}{ Immunological biomarkers } \\
\hline $\lg A(\mu \mathrm{g} / \mathrm{g}$ fw) $) \neq$ & $20(2)$ & $129 \cdot 3$ & $36 \cdot 2$ & 20 & $189 \cdot 3$ & $35 \cdot 1$ & $0 \cdot 241$ \\
\hline $\mathrm{PGE}_{2}(\mathrm{pg} / \mathrm{g} \mathrm{fw})$ & 20 & $498 \cdot 2$ & $56 \cdot 5$ & 20 & $486 \cdot 1$ & $39 \cdot 0$ & 0.860 \\
\hline TNF- $\alpha(p g / g$ fw) $) \S$ & $20(1)$ & $9 \cdot 45$ & $2 \cdot 74$ & 20 & $15 \cdot 53$ & $6 \cdot 36$ & 0.388 \\
\hline Calprotectin $(\mu \mathrm{g} / \mathrm{g} \mathrm{fw})$ & 20 & $34 \cdot 23$ & $17 \cdot 09$ & $20(3)$ & $26 \cdot 44$ & $4 \cdot 89$ & 0.666 \\
\hline
\end{tabular}

$\mathrm{fw}$, fresh digesta weight; BCFA, branched-chain fatty acid.

* The sample size used for calculating the descriptive statistics including the number of samples below the detection limits (given in parenthesis). For calculation of the mean values, the data below detection limits were set to half of the limit value. Two-sample $t$ test was used to compare the mean values between the two groups.

†Detection limits: $1.2 \times 10^{2}$ cells $/ \mathrm{g}$.

¥Detection limits: $5 \cdot 1 \times 10^{1}$ cells $/ \mathrm{g}$.

$\S$ A $P$-value $<0.05$ was considered to indicate significant difference between the groups.

|| Detection limits: $0.1 \mathrm{mmol} / \mathrm{kg}$.

9 Detection limits: $30 \mathrm{nmol} / \mathrm{kg}$.

${ }^{\star \star}$ Detection limits: $15 \mathrm{nmol} \mathrm{g} / \mathrm{kg}$.

†† Detection limits: $10 \mathrm{mg} / \mathrm{kg}$.

㧊 Detection limits: $0.4 \mu \mathrm{g} / \mathrm{kg}$

$\S \S$ Detection limits: $0 \mathrm{pg} / \mathrm{g}$. 
Table 6. Pearson correlation coefficients $(r)$ and $P$-values for testing whether the correlation is zero or not for faecal and clinical measurements combining data from both the groups

\begin{tabular}{|c|c|c|c|c|c|c|c|c|c|c|c|c|c|c|c|}
\hline \multirow{2}{*}{$\begin{array}{l}\text { Faecal parameters... } \\
\text { Clinical parameters }\end{array}$} & \multicolumn{3}{|c|}{$\begin{array}{l}\text { Concentrations of } \\
\text { di- and hydroxy } \\
\text { acids }\end{array}$} & \multicolumn{3}{|c|}{$\begin{array}{l}\text { Concentrations of } \\
\text { phenolics }\end{array}$} & \multicolumn{3}{|c|}{$\begin{array}{l}\text { Concentrations } \\
\text { of sterols }\end{array}$} & \multicolumn{3}{|c|}{$\begin{array}{l}\text { Total microbial } \\
\text { counts }\end{array}$} & \multicolumn{3}{|c|}{$\begin{array}{l}\text { Numbers of } \\
\text { Bacteroides }\end{array}$} \\
\hline & $r$ & $P^{\star}$ & $n \dagger$ & $r$ & $P^{\star}$ & $n \dagger$ & $r$ & $P^{\star}$ & $n \dagger$ & $r$ & $P^{\star}$ & $n \dagger$ & $r$ & $P^{\star}$ & $n \dagger$ \\
\hline CRP & 0.51 & 0.04 & 16 & 0.53 & 0.04 & 16 & & NS & & -0.51 & 0.04 & 16 & & NS & \\
\hline Concentrations of IL-6 & 0.51 & 0.04 & 16 & 0.62 & 0.01 & 16 & & NS & & & NS & & & NS & \\
\hline Concentrations of TNF- $\alpha$ & & NS & & & NS & & 0.77 & 0.0002 & 16 & 0.42 & 0.006 & 40 & & NS & \\
\hline Waist circumference & 0.52 & 0.04 & 16 & & NS & & & NS & & & NS & & -0.31 & 0.05 & 40 \\
\hline Weight & 0.56 & 0.02 & 16 & 0.60 & 0.01 & 16 & & NS & & & NS & & -0.26 & 0.09 & 40 \\
\hline
\end{tabular}

CRP, C-reactive protein.

*A $P$-value $<0.05$ indicates significant association.

† Values refer to the number of observations for which measurements on both parameters are available.

with some of the microbial metabolites, i.e. concentrations of phenolics $(P=0.04$ and 0.01$)$ and di- and hydroxy acids $(P=0.04$ and 0.04$)$, whereas serum TNF- $\alpha$ was associated with the total number of bacteria and the faecal concentrations of sterols $(P=0.006$ and $P<0.001)$. An inverse correlation between the numbers of faecal Bacteroides and waist circumference $(P=0.05)$ as well as weight $(P=0.09)$ was noted. In addition, an inverse correlation between the total faecal microbial counts and serum CRP $(P=0 \cdot 04)$ was found (Table 6$)$.

\section{Discussion}

The obese subjects included in the present study were found to represent typical characteristics regarding their fasting satietyregulating hormones, metabolic disturbances and inflammatory biomarkers. In accordance with previous findings, the plasma TAG concentrations were higher and HDL-cholesterol was lower in obese subjects than in normal weight subjects ${ }^{(20)}$. Moreover, the increased insulin concentrations in the study subjects may indicate insulin resistance. The elevated plasma leptin levels in the present study are also in line with previous findings ${ }^{(21)}$ indicating leptin resistance in obese subjects ${ }^{(21)}$. Circulating ghrelin, which has the opposite effect to leptin, is, however, decreased as reported also by Tschop et al. ${ }^{(22)}$. Adipose tissue has been described as an origin for pro-inflammatory cytokines such as IL- 6 and TNF- $\alpha{ }^{(23)}$. It has been proposed that hypoxia caused by enlarged adipocyte size may underlie an inflammatory response, increasing IL- 6 and TNF- $\alpha$ production and decreasing secretion of anti-inflammatory adiponectin ${ }^{(24)}$. Increased serum IL- 6 concentrations are reported to be associated with visceral adiposity, whereas serum TNF- $\alpha$ showed more associations with total body fatness ${ }^{(20,25)}$. The present study also indicated a correlation between serum IL-6 and waist circumference, while serum TNF- $\alpha$ correlated with faecal sterol concentrations. The latter phenomenon possibly indicating of a feedback signalling from the stressed adipocytes, indicated by secretion of TNF- $\alpha$, to the intestinal tissue to reduce absorption of sterols forms the diet, thus perhaps resulting in increased concentrations present in the faeces. Alternatively, in rodent model, inflammation has shown to impair reverse cholesterol transport to faeces ${ }^{(26)}$. High-fat feeding has shown to increase gut permeability of bacterial lipopolysaccharides to plasma, which in turn triggers low-grade inflammation and obesity-associated disorders ${ }^{27,28)}$. Anti-inflammatory adiponectin concentrations are typically decreased in obesity ${ }^{(29)}$; however, in the present study, the decrease was not statistically significant. It is of interest that, despite the systemic inflammatory status, the measured faecal immunological biomarkers were not affected by obesity. Previously, it has been described that concentrations of faecal PGE 2 may be affected by age ${ }^{(30)}$, and furthermore, that faecal IgA concentrations may be elevated during the allergy season in subjects allergic to birch pollen ${ }^{(31)}$. Both calprotectin and TNF- $\alpha$ are used to monitor the state of intestinal inflammation, and antibodies specific to TNF- $\alpha$ are also used as treatment to suppress the intestinal inflammation, in patients with inflammatory bowel disease and ulcerative colitis ${ }^{(32-34)}$.

Only relatively small changes were detected in the faecal microbial composition between the obese and normal weight groups. However, the fermentation pattern in obese subjects is more pronounced in protein than carbohydrate fermentation as suggested by increased concentrations of BCFA, phenolics and a tendency for increased ammonium concentrations ${ }^{(35)}$. Surprisingly, in spite of the indirect indications of elevated amounts of protein fermentation, less sulphate-reducing bacteria were detected in the obese subjects. In accordance with previous observations, the levels of Bacteroides were decreased in the obese subjects ${ }^{(10)}$. Interestingly, the waist circumference was inversely correlated with the numbers of Bacteroides, underlining the possible role of Bacteroides in the absence of adiposity. Increased numbers of faecal Bacteroidetes have also been detected in elderly over 70 years of age than in young adults ${ }^{(36)}$. In a recently published retrospective study on children at risk of developing allergy, less bifidobacteria and more Staphylococcus aureus were found in the faeces of children that later became overweight ${ }^{(37)}$. In the present study, the levels of $S$. aureus were not determined, but the levels of bifidobacteria were similar in both the normal weight and obese subjects. Furthermore, other associations between chronic conditions such as irritable bowel syndrome and intestinal microbiota have also been reported ${ }^{(38)}$.

The elevated concentrations of many residual microbial metabolites, both originating from carbohydrate and protein fermentation, in the faeces suggest a different fermentation profile in the colon of the obese subjects. Previously, it has been described that faecal SCFA are found in higher levels in obese subjects than in lean subjects ${ }^{(39)}$, while, in the present study, the difference was statistically significant only in the faecal concentrations of BCFA. Recently, Samuel et al. ${ }^{(40)}$ have indicated SCFA as signalling molecules for enteroendocrine cells to produce PYY and thus decreasing gut motility and further 
increasing SCFA absorption and energy extraction from the gut lumen. Microbial metabolites may also regulate food intake differently in obese and in lean subjects, as has been indicated by rat studies ${ }^{(41)}$. Many metabolites resulting from putrefaction, such as phenols ${ }^{(42)}$, have been linked with health risks, such as colon cancer ${ }^{(43)}$, whereas metabolites, such as butyrate, may be chemopreventive in colon carcinogenesis ${ }^{(44)}$. Obesity has been identified as a risk factor for the development of colon cancer $^{(45)}$; the higher faecal levels of BCFA and phenols could potentially be a partial explanation for these epidemiological observations. Concentrations of faecal butyrate were not found to be decreased in the obese subjects in the present study. In summary, the changed microbial metabolite profile in the faeces of obese subjects may reflect the adaptation of the microbial community to the different nutrients available.

In the present study, faecal phenolics and lactic acid were found to be associated with the blood inflammatory biomarkers, CRP and IL-6. It remains to be determined whether or not these coinciding changes are somehow causally linked to each other. L-lactate is generally a signal of anaerobic metabolism in tissues and thus may induce inflammatory response in adipose tissues. Lactic acid is also produced by many different GI microbes and is typically utilised by other intestinal microbes ${ }^{(46)}$ and does not accumulate in the faeces of healthy subjects. If, however, lactate is accumulated in the lower GI tract due to an imbalance in the lactate-producing and lactate-utilising bacteria, it can be absorbed into the blood circulation either by passive diffusion (D-lactate) or via the monocarboxylate transporter (L-lactate) ${ }^{(47)}$. Therefore, lactic acid originating from intestinal fermentation can have also systemic effects, e.g. with muscle cells $^{(48)}$. Unfortunately, plasma lactate levels were not analysed in the present study. In obesity, elevated blood lactate concentrations are suggested to originate from increased lactate production by adipocytes ${ }^{(49)}$. However, the postprandial rise in circulating lactate may be partly explained by the intestinal lactate production. Chronic hyperlactaemia has been suggested to have a role in the development of insulin resistance in muscle cells $^{(48)}$. Excessive amounts of lactic acid in the blood circulation have been shown to cause neurotoxicity and cardiac $\operatorname{arrhythmia}^{(50,51)}$. Also dietary or microbe-derived phenolics can be absorbed from the GI tract, but their uptake can be incomplete $^{(52)}$. In addition to microbial metabolites, structural microbe-derived products, such as lipopolysaccharides, have been recently suggested to affect the development of metabolic diseases in animal models ${ }^{(53)}$.

Overall, the changes in the microbial fermentation patterns, including increased faecal phenolics and lactic acid concentrations, described in the obese subjects most probably have an impact on host physiology including the systemic inflammatory condition. Future studies should focus on studying whether these obesity-associated intestinal parameters could be a potential therapeutic target for decreasing obesity-associated systemic effects.

\section{Acknowledgements}

The present research received no external funding, apart from the support of Danisco A/S. The authors are indebted to the participants of the study for their cooperation and assistance. The authors thank Markku Saarinen, Antti Kaipainen, Martti Marjamaa, Päivi Nurminen, Heli Putaala, Brita Mäki, Kirsi
Stenström, Eeva Linblom and Tiina Laamanen for the various laboratory analyses. Essi Sarkkinen, Tarja Niskanen and Henna Karvonen from Foodfiles Ltd are thanked for the practical arrangements; and Akra-Numero Research and Consultancy Centre, India, for the statistical analysis. All authors contributed to the preparation of the manuscript. K. T. contributed to the planning of the study, data management, coordination of the manuscript preparation and data interpretation. A. C. O. contributed to the microbial analyses, manuscript preparation and data interpretation. N. R. coordinated the planning of the study and contributed to manuscript preparation and data interpretation. There is no conflict of interest.

\section{References}

1. Peeters A, Barendregt JJ, Willekens F, et al. (2003) Obesity in adulthood and its consequences for life expectancy: a life-table analysis. Ann Intern Med 138, 24-32.

2. Mikkola I, Keinanen-Kiukaanniemi S, Laakso M, et al. (2007) Metabolic syndrome in connection with BMI in young Finnish male adults. Diabetes Res Clin Pract 76, 404-409.

3. Esteghamati A, Khalilzadeh O, Anvari M, et al. (2008) Metabolic syndrome and insulin resistance significantly correlate with body mass index. Arch Med Res 39, 803-808.

4. Yudkin JS, Stehouwer CDA, Emeis JJ, et al. (1999) C-reactive protein in wealthy subjects: associations with obesity, insulin resistance, and endothelial dysfunction - a potential role for cytokines originating from adipose tissue? Arterioscler Thromb Vasc Biol 19, 972-978.

5. Dandona P, Aljada A \& Bandyopadhyay A (2004) Inflammation: the link between insulin resistance, obesity and diabetes. Trends Immunol 25, 4-7.

6. Bahceci M, Gokalp D, Bahceci S, et al. (2007) The correlation between adiposity and adiponectin tumor necrosis factor alpha, interleukin-6 and high sensitivity C-reactive protein levels. Is adipocyte size asssociated with inflammation in adults? $J$ Endocrinol Invest 30, 210-214.

7. Festa A, D'Agostino R, Williams K, et al. (2001) The relation of body fat mass and distribution to markers of chronic inflammation. Int J Obes 25, 1407-1415.

8. Diamond JM \& Karasov WH (1987) Adaptive regulation of intestinal nutrient transporters. Proc Natl Acad Sci USA 84, 2242-2245.

9. Diamond J (1991) Evolutionary design of nutrient absorption: enough but not too much. News Physiol Sci 6, 92-96.

10. Ley RE, Turnbaugh PJ, Klein S, et al. (2006) Microbial ecology - human gut microbes associated with obesity. Nature 444, 1022-1023.

11. Turnbaugh PJ, Ley RE, Mahowald MA, et al. (2006) An obesityassociated gut microbiome with increased capacity for energy harvest. Nature 444, 1027-1031.

12. Lyly M, Soini E, Rauramo U, et al. (2004) Perceived role of fibre in a healthy diet among Finnish consumers. J Hum Nutr Diet 17, 231-239.

13. Cristie WW (1989) Gas Chromatography and Lipids, A Practical Guide. Glasgow: The Oily Press Ltd.

14. Knust U, Erben G, Spiegelhalder B, et al. (2006) Identification and quantitation of phenolic compounds in faecal matrix by capillary gas chromatography and nano-electrospray mass spectrometry. Rapid Commun Mass Spectrom 20, 3119-3129.

15. Miller RS \& Hoskins LC (1981) Mucin degradation in human colon ecosystems. Fecal population densities of mucindegrading bacteria estimated by a 'most probable number' method. Gastroenterology 81, 759-765. 
16. Ouwehand AC, Tiihonen K, Saarinen M, et al. (2009) Influence of a combination of Lactobacillus acidophilus NCFM and lactitol on healthy elderly: intestinal and immune parameters. Br J Nutr 101, 367-375.

17. Saarinen M (2002) Determination of biogenic amines as dansyl derivatives in intestinal digesta and feces by reversed phase HPLC. Chromatographia 55, 297-300.

18. Apajalahti JH, Kettunen H, Kettunen A, et al. (2002) Cultureindependent microbial community analysis reveals that inulin in the diet primarily affects previously unknown bacteria in the mouse cecum. Appl Environ Microbiol 68, 4986-4995.

19. Apajalahti JH, Sarkilahti LK, Maki BR, et al. (1998) Effective recovery of bacterial DNA and percent-guanine-plus-cytosinebased analysis of community structure in the gastrointestinal tract of broiler chickens. Appl Environ Microbiol 64, 4084-4088.

20. Couillard C, Bergeron N, Prud'homme D, et al. (1998) Postprandial triglyceride response in visceral obesity in men. Diabetes 47, 953-960.

21. Considine RV (1997) Leptin and obesity in humans. Eat Weight Disord 2, 61-66.

22. Tschop M, Weyer C, Tataranni PA, et al. (2001) Circulating ghrelin levels are decreased in human obesity. Diabetes 50, 707-709.

23. Compher C \& Badellino KO (2008) Obesity and inflammation: lessons from bariatric surgery. JPEN J Parenter Enteral Nutr 32, 645-647.

24. Trayhurn P, Wang B \& Wood IS (2008) Hypoxia and the endocrine and signalling role of white adipose tissue. Arch Physiol Biochem 114, 267-276.

25. Cartier A, Lemieux I, Almeras N, et al. (2008) Visceral obesity and plasma glucose-insulin homeostasis: contributions of interleukin-6 and tumor necrosis factor-alpha in men. $J$ Clin Endocrinol Metab 93, 1931-1938.

26. McGillicuddy FC, de la Llera MM, Hinkle CC, et al. (2009) Inflammation impairs reverse cholesterol transport in vivo. Circulation 119, 1135-1145.

27. Cani PD, Amar J, Iglesias MA, et al. (2007) Metabolic endotoxemia initiates obesity and insulin resistance. Diabetes 56, 1761-1772.

28. Cani PD, Bibiloni R, Knauf C, et al. (2008) Changes in gut microbiota control metabolic endotoxemia-induced inflammation in high-fat diet-induced obesity and diabetes in mice. Diabetes 57, 1470-1481.

29. Weyer C, Funahashi T, Tanaka S, et al. (2001) Hypoadiponectinemia in obesity and type 2 diabetes: close association with insulin resistance and hyperinsulinemia. J Clin Endocrinol Metab 86, 1930-1935.

30. Tiihonen K, Tynkkynen S, Ouwehand A, et al. (2008) The effect of ageing with and without non-steroidal anti-inflammatory drugs on gastrointestinal microbiology and immunology. $\mathrm{BrJ}$ Nutr 100, 130-137.

31. Ouwehand AC, Nermes M, Collado MC, et al. (2009) Specific probiotics alleviate allergic rhinitis during the birch pollen season. World J Gastroenterol 15, 3261-3268.

32. Foell D, Wittkowski H \& Roth J (2009) Monitoring disease activity by stool analyses: from occult blood to molecular markers of intestinal inflammation and damage. Gut 58, 859-868.

33. Tsianos EV \& Katsanos K (2009) Do we really understand what the immunological disturbances in inflammatory bowel disease mean? World J Gastroenterol 15, 521-525.

34. Yadav PK \& Liu Z (2009) Current strategies for the treatment of ulcerative colitis. Recent Pat Inflamm Allergy Drug Discov 3, 65-72.

35. Cummings JH \& Macfarlane GT (1991) The control and consequences of bacterial fermentation in the human colon. J Appl Bacteriol 70, 443-459.

36. Makivuokko H, Tiihonen K, Tynkkynen S, et al. (2009) The effect of age and non-steroidal anti-inflammatory drugs on human intestinal microbiota composition. Br J Nutr (Epublication ahead of print version 25 August 2009).

37. Kalliomaki M, Collado MC, Salminen S, et al. (2008) Early differences in fecal microbiota composition in children may predict overweight. Am J Clin Nutr 87, 534-538.

38. Malinen E, Rinttila T, Kajander K, et al. (2005) Analysis of the fecal microbiota of irritable bowel syndrome patients and healthy controls with real-time PCR. Am J Gastroenterol 100, 373-382.

39. Schwiertz A, Taras D, Schafer K, et al. (2009) Microbiota and SCFA in lean and overweight healthy subjects. Obesity (Silver Spring) (Epublication ahead of print version 4 June 2009).

40. Samuel BS, Shaito A, Motoike T, et al. (2008) Effects of the gut microbiota on host adiposity are modulated by the short-chain fatty-acid binding $G$ protein-coupled receptor, Gpr41. Proc Natl Acad Sci USA 105, 16767-16772.

41. Bray GA (2000) Afferent signals regulating food intake. Proc Nutr Soc 59, 373-384.

42. Hughes R \& Rowland IR (2000) Metabolic activities of the gut microflora in relation to cancer. Microb Ecol Health Dis 11, $179-185$.

43. Rafter JJ (2002) Scientific basis of biomarkers and benefits of functional foods for the reduction of disease risk: cancer. $\mathrm{Br} \mathrm{J}$ Nutr 88, S219-S224.

44. Scheppach W \& Weiler F (2004) The butyrate story: old wine in new bottles. Curr Opin Clin Nutr Metab Care 7, 563-567.

45. Larsson SC \& Wolk A (2007) Obesity and colon and rectal cancer risk: a meta-analysis of prospective studies. Am J Clin Nutr 86, 556-565.

46. Duncan SH, Louis P \& Flint HJ (2004) Lactate-utilizing bacteria, isolated from human feces, that produce butyrate as a major fermentation product. Appl Environ Microbiol 70, 5810-5817.

47. Ritzhaupt A, Wood IS, Ellis A, et al. (1998) Identification and characterization of a monocarboxylate transporter (MCT1) in pig and human colon: its potential to transport L-lactate as well as butyrate. $J$ Physiol (Pt 3), 513, 719-732.

48. Lombardi AM, Fabris R, Bassetto F, et al. (1999) Hyperlactatemia reduces muscle glucose uptake and GLUT-4 mRNA while increasing (E1alpha)PDH gene expression in rat. Am J Physiol 276, E922-E929.

49. DiGirolamo M, Newby FD \& Lovejoy J (1992) Lactate production in adipose tissue: a regulated function with extraadipose implications. FASEB J 6, 2405-2412.

50. Chan L, Slater J, Hasbargen J, et al. (1994) Neurocardiac toxicity of racemic D,L-lactate fluids. Integr Physiol Behav Sci 29, 383-394.

51. Vella A \& Farrugia G (1998) D-Lactic acidosis: pathologic consequence of saprophytism. Mayo Clin Proc 73, 451-456.

52. Jenner AM, Rafter J \& Halliwell B (2005) Human fecal water content of phenolics: the extent of colonic exposure to aromatic compounds. Free Radic Biol Med 38, 763-772.

53. Reigstad CS, Lunden GO, Felin J, et al. (2009) Regulation of serum amyloid A3 (SAA3) in mouse colonic epithelium and adipose tissue by the intestinal microbiota. PLoS One 4, e5842.

54. Makivuokko $\mathrm{H}$, Nurmi J, Nurminen $\mathrm{P}$, et al. (2005) In vitro effects on polydextrose by colonic bacteria and caco-2 cell cyclooxygenase gene expression. Nutr Cancer 52, 94-104.

55. Byun R, Nadkarni MA, Chhour KL, et al. (2004) Quantitative analysis of diverse Lactobacillus species present in advanced dental caries. J Clin Microbiol 42, 3128-3136.

56. Song Y, Liu C \& Finegold SM (2004) Real-time PCR quantitation of clostridia in feces of autistic children. Appl Environ Microbiol 70, 6459-6465.

57. Nakanishi Y, Murashima K, Ohara H, et al. (2006) Increase in terminal restriction fragments of Bacteroidetes-derived $16 \mathrm{~S}$ rRNA genes after administration of short-chain fructooligosaccharides. Appl Environ Microbiol 72, 6271-6276. 